\title{
Wear Resistance Under High Load Forces of Four Different Polyethylene Terephthalate Glycol Vacuum-Formed Orthodontic Retainers
}

\author{
DANA CRISTINA BRATU1', VLAD FLORIN VINATU2*, SILVIA IZABELLA POP3*, POMPILIU HORATIU PETRESCU4, \\ CATALIN PETRU SIMON ${ }^{5}$, GEORGE POPA ${ }^{1}$ \\ ${ }^{1}$ Victor Babes University of Medicine and Pharmacy, Faculty of Dental Medicine, Department of Orthodontics, 9 Revolutiei din \\ 1989 Blvd., 300070, Timisoara, Romania \\ 2Politehnica University of Timisoara, Faculty of Mechanics, Department of Mechanical Machinery, Equipment and Transports, \\ 1 Mihai Viteazu Blvd., 300222, Timisoara, Romania \\ 3University of Medicine, Pharmacy, Science and Technology of Tirgu Mures,Faculty of Dental Medicine, Department of Orthodontics, \\ 38 Gheorghe Marinescu Str., Tirgu Mures, 540139, Romania \\ ${ }^{4}$ Victor Babes University of Pharmacy, Faculty of Medicine, Department of Orthopedics and Traumatology, 2 Eftimie Murgu Sq., \\ 300041, Timisoara, Romania \\ ${ }^{5}$ Victor Babes University of Medicine and Pharmacy, Faculty of Medicine, Department of Anatomy and Embryology, 2 Eftimie \\ Murgu Sq., 300041, Timisoara, Romania
}

\begin{abstract}
The aim of our study was to determine the wear resistance of vacuum-formed retainers (VFRs) made out of polyethylene terephthalate glycol (PETG), from four different manufacturers (Essix, Leone, Erkodent, BioArt), under high load forces (600 N), for 10000 cycles. Forty thermoplastic sheets were divided in four groups, each group consisting of a set of ten sheets from each manufacturer, thermoformed on two matching study models with an ideal occlusion. The Instron 8874 equipment was used to simulate the accelerated wear of VFR surfaces. The surfaces of the VFRs were visually inspected using a KEYENCE VHX-600 digital microscope, but this proved difficult because of the surface shine. 3D models were generated using a GOM industrial laser surface scanner. Several wear areas were identified, having various degrees of roughness, with no evident tear points or perforations. One-way ANOVA analysis showed no statistically significant differences in net mass loss between the four groups.
\end{abstract}

Keywords: wear resistance, polyethylene terephthalate glycol, vacuum-formed retainer, orthodontics

The demand for orthodontic appliances that are more esthetically pleasing has significantly increased in the last decades, as a result of the growing number of adult patients that seek orthodontic treatment [1-3].

One of the main concerns after the completion of the orthodontic treatment is to stabilize and maintain the teeth in their final position, using proper retention appliances. Relapse is defined as the change that occurs in tooth position or in arch relationship after the end of the active orthodontic treatment [4-6]. Several factors have been incriminated in the mechanism of orthodontic relapse: occlusal forces, forces generated by the gingival, periodontal and orofacial soft tissues, as well as posttreatment growth and normal age-related changes [6-11]. The retention phase is particularly challenging for the clinicians because some of these factors are manageable only to some extent, especially when post-treatment growth factors are involved. In practice, various types of retention appliances are used, each with its own advantages and disadvantages: bonded retainers, Hawley retainers, thermoplastic (vacuum-formed) retainers and positioners (custom-made or prefabricated).

The vacuum-formed retainers (VFRs) are removable appliances, made out of clear thermoplastic materials (eg. polypropylene polymers, polyethylene polymers, polyvinyl chloride polymers). These retainers address the patient's demand for high esthetics, ease of use and optimal oral hygiene. From the clinician's perspective, VFRs are more cost-effective, have a higher compliance rate and even reduce the chance of relapse in some cases (corrections of the axis of the lower incisors) when compared to Hawley retainers [12-15].

In order to be effective and to prevent relapse for longer periods of time, the retainers have to maintain their structural integrity and their physical properties. However, several studies published in literature have reported poor resistance to wear for some types of VFRs [16-20]. Mechanical wear, defined as the loss of material from solid surfaces as a result of mechanical interaction, is a complex process in the clinical context, because of the patient's individual patterns of occlusal interaction and parafunctional habits, mechanisms which are harder to predict or to control.

The aim of our study was to determine the wear resistance of VFRs made out of polyethylene terephthalate glycol (PETG) from four differentmanufacturers, under high load forces, simulating the high bite force patterns produced in bruxism, a very common parafunctional habit.

\section{Experimental part}

Materials and methods

For this study we used forty thermoplastic sheets ( 1.0 $\mathrm{mm}$ thick square sheets of $125 \times 125 \mathrm{~mm}$ ) from four different manufacturers, made out of polyethylene terephthalate glycol (PETG), recommended for the vacuum-forming of retainer appliances (Table 1 ). The samples were divided in four groups, each group consisting of a set of ten thermoplastic sheets from each

* email: vlad@mea-edu.ro, Phone: +40 726 349298; kecsetisilvia@yahoo.com, Phone: +40 742013062 
Table 1

TYPE OF MATERIALS USED IN THE STUDY

\begin{tabular}{|l|l|l|}
\hline Manufacturer & Product name & Country \\
\hline Dentsply Raintree Essix & Essix ACE & USA \\
\hline Leone & Máteriale & Italy \\
& Biocompatibile & \\
& Termoformabile & \\
\hline Erkodent & Erkodur (clear) & Germany \\
\hline Bio-Airt & Crystal $^{-}$ & Brazil $^{-}$ \\
\hline
\end{tabular}

manufacturer (five sheets for the upper dental arch and five for the lower dental arch).

The thermoplastic sheets were vacuum-formed in pairs on two matching, ideal dental arches, with an ideal occlusion. For the study models we opted for a bicomponent model resin (Exakto-Form, Bredent), which had good mechanical properties and accurate reproduction of details.

The vacuum thermoforming equipment used to create the VFRs was PlastVac P7 (Bio-Art, Brazil), that consisted of a rotating system for fixing the thermoplastic sheets with a carbon resistance for rapid and uniform heating of the sheets. We followed the instructions recommended by the manufacturers in the vacuum-forming process of each thermoplastic sheet.

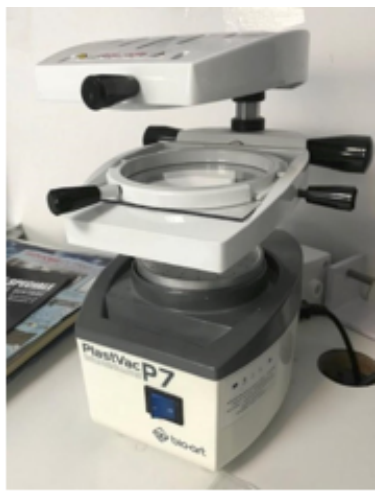

Fig. 1. Vacuum-forming machine PlastVac P7 (Bio-Art)

The Instron 8874 equipment, with a bi-axial servo hydraulic testing system that could combine axial and torsion dynamic actuator in the upper crosshead module and a t-slot clenching system guided by the precision twincolumn aligned frame was used for the wear tests, to simulate a tooth clenching scenario for patients with bruxism. The machine was set at $1 \mathrm{~Hz}, 1000$ seconds, an amplitude of 3 degrees, $600 \mathrm{~N}$ loading capacity and 10000 cycles for each pair of VFRs, to simulate the accelerated wear and tear of the thermoformed surfaces (Fig. 2 and Fig. 3).

A custom jig with metal rods was designed to fix the study models in the testing machine. Each pair of VFRs were set in place on the corresponding upper and lower study model, simulating real bite conditions, similar to those in the patient's oral cavity.

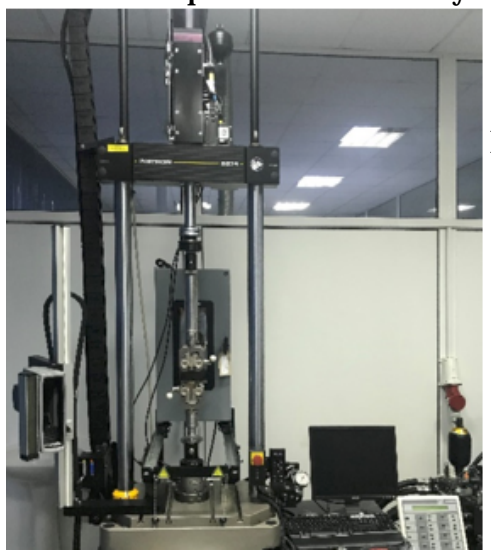

Fig. 2. Wear testing machine Instron 8874.

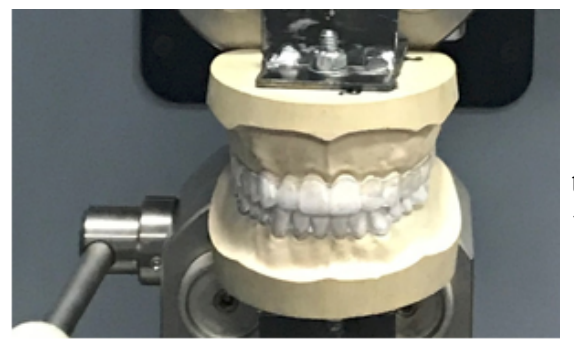

Fig. 3. The study models fixed in the testing machine, with the VFRs set in place

The custom jig consisted of two separate components: an upper and a lower component for each study model, each having a metal plate with screws that attach to the study models on one end and a metal rod of $12 \mathrm{~mm}$ in diameter welded on the opposite end, acting as a clamping support for the testing machine.

Before the initial mechanical wear test, all samples were weighted using an analytical analog balance scales (ZATKLADY) with 5 decimal places $(0.00000 \mathrm{~g})$ to identify the finest differences in mass.

For an accurate assessment of the changes in the mass of the samples, a handling protocol for sample manipulation, before and after testing, was established and consisted in using a low-pressure blower to remove any waste that occurred during testing. The samples were handled using standard tweezers.

After the wear test, the surfaces of the VFRs were visually inspected and characterized, using a KEYENCE VHX-600 digital microscope.

A GOM industrial laser surface scanner was utilized to scan the surfaces of the VFRs and the 3D models were generated by the GOM Inspect 3D software using the 3 overlapping marker points method for interior and exterior surfaces scanning. The scanner detected all extruded or in-depth irregularities. The surface shine was reduced using a standard coating of white powder spray.

\section{Statistical analysis}

The data were statistically analysed using specialized software (IBM SPSS, version 24, SPSS Inc., Chicago). Oneway ANOVA analysis was conducted to test for differences in net mass loss after wear simulations between the four groups, in each arch $(\alpha=0.05)$. The data had no outliers, as assessed by boxplot, with one exception in the Bio-Art upper arch group. The outlier was included in the analysis, as we concluded that it did not affect the final result, the outlier $(0.018 \mathrm{mg})$ was not an extreme outlier and it was close to the next largest value in the group $(0.015 \mathrm{mg})$. Including the outlier, excluding it or modifying it with the next largest value din not affect the overall results. The data was normally distributed, as assessed by ShapiroWilk's test ( $p>0.05)$ and the assumption of homogeneity was not violated, as assessed by Levene's test for equality of variances ( $p=0.463$ for the groups in the upper arch and $p=0.177$ for the groups in the lower arch).

\section{Results and discussions}

The net mass loss (milligrams) after the wear tests for the VFR groups in each arch are visually presented as box plots in figure 4 and figure 5 and as numerical descriptive statistics in Table 2 and Table 3.

The total mean of net mass loss in the upper arch groups $(0.153 \pm 0.048)$ was lower than the total mean of the lower arch groups $(0.549 \pm 0.075)$, possibly, because of the difference in load distribution between the two different surfaces (upper and lower), taking into account not only the vertical load, but also the torque component. A larger sample might clarify why the wear was more prominent in the VFRs in the lower arch, but as this was not the 


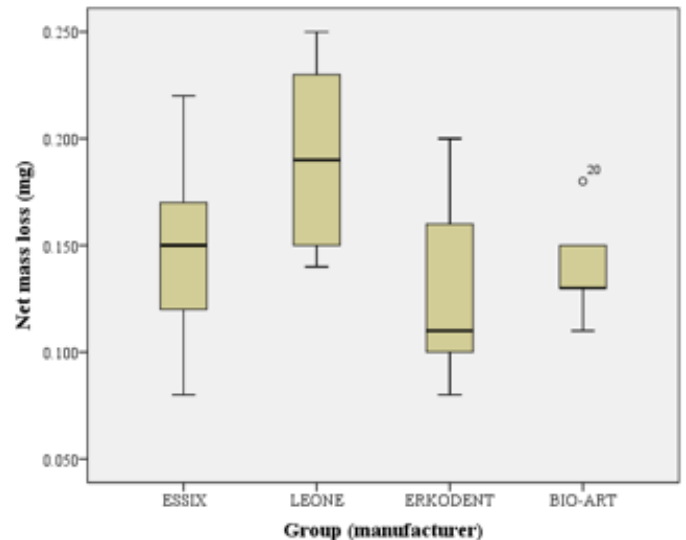

Fig. 4. Box plot showing the descriptive statistics for the VFR groups for the upper arch

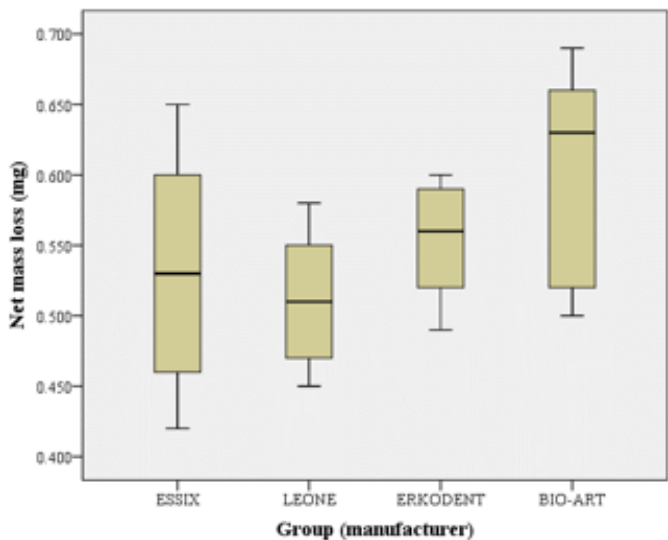

Fig. 5. Box plot showing the descriptive statistics for the VFR groups for the lower arch.

Table 2

NET MASS LOSS (MILLIGRAMS) AND DESCRIPTIVE STATISTICS FOR THE VFR GROUPS FOR THE UPPER ARCH

\begin{tabular}{|c|c|c|c|c|c|c|c|c|}
\hline \multirow{2}{*}{$\begin{array}{c}\text { Groups } \\
\text { [Upper arch] }\end{array}$} & \multirow[b]{2}{*}{$\mathrm{N}$} & \multirow[b]{2}{*}{ Mean } & \multirow[b]{2}{*}{$\mathrm{SD}$} & \multirow[b]{2}{*}{$\begin{array}{l}\text { Std. } \\
\text { Error }\end{array}$} & \multicolumn{2}{|c|}{$95 \%$ CI for Mean } & \multirow[b]{2}{*}{ Minimum } & \multirow[b]{2}{*}{ Maximum } \\
\hline & & & & & $\begin{array}{l}\text { Lower } \\
\text { Bound }\end{array}$ & $\begin{array}{l}\text { Upper } \\
\text { Bound }\end{array}$ & & \\
\hline ESSIX & 5 & 0.148 & 0.053 & 0.024 & 0.083 & 0.213 & 0.08 & 0.22 \\
\hline LEONE & 5 & 0.192 & 0.048 & 0.022 & 0.132 & 0.252 & $0.14^{-}$ & 0.25 \\
\hline ERKODENT & 5 & 0.130 & 0.049 & 0.022 & 0.069 & 0.191 & 0.08 & 0.20 \\
\hline BIO-ART & 5 & 0.140 & 0.026 & 0.012 & 0.107 & 0.173 & $0.11^{-}$ & 0.18 \\
\hline Total & 20 & 0.153 & 0.048 & $0.011^{-}$ & 0.130 & 0.175 & 0.08 & 0.25 \\
\hline
\end{tabular}

SD - Std. Deviation, CI - Confidence Interval

objective of the present study, we cannotdraw any relevant conclusions regarding these finds.

The one-way ANOVA analysis showed no statistically significant differences in net mass loss after wear simulations, between the four groups $(p=0.183$ for the groups in the upper arch and $p=0.300$ for the groups in the lower arch) (Table 4).

Visually inspecting and characterizing surfaces, using the KEYENCE VHX-600 digital microscope proved difficult on VFR materials because of the material shine (Fig. 6). However, several wear areas were identified, having various degrees of roughness, but, overall, consistent between the four groups.

No important modifications were observed on the generated 3D models of the tested VFRs, using the GOM surface camera scanner and GOM Inspect software (Fig. 7).
Several studies in the literature have addressed the wear resistance of different types of VFR materials, but the authors employed different protocols for their studies and different loading forces [16,18-25]. These studies used steatite ceramic abraders and conducted surface profilometry analyses, measuring the wear depth of each sample to evaluate the wear resistance. All the samples consisted of flat surfaces of VFR materials.

Raja etal. [18] and Moshkelgosha etal. [20] subjected the materials to a force of $460 \mathrm{~g}(\sim 4.5 \mathrm{~N})$, for 1000 wear cycles, Ahdab [21] used a load of $45 \pm 1.3 \mathrm{~N}$, for 2500 cycles, while Gardner et al. [16] used a force of $25 \mathrm{~kg}$ $(\sim 245 \mathrm{~N})$, for 1000 cycles.

Unlike the previous studies we wanted to test the wear resistance of VFR materials set in place on study models, replicating closer to real-life conditions of the upper and lower jaw movements, under heavy loads, similar to high bite force patterns produced in bruxism. In order to simulate

Table 3

NET MASS LOSS (MILLIGRAMS) AND DESCRIPTIVE STATISTICS FOR THE VFR GROUPS FOR THE LOWER ARCH

\begin{tabular}{|c|c|c|c|c|c|c|c|c|}
\hline \multirow{2}{*}{$\begin{array}{c}\text { Groups } \\
\text { [Lower arch] }\end{array}$} & \multirow[b]{2}{*}{$\mathrm{N}$} & \multirow[b]{2}{*}{ Mean } & \multirow[b]{2}{*}{$\mathrm{SD}$} & \multirow{2}{*}{$\begin{array}{l}\text { Std. } \\
\text { Error }\end{array}$} & \multicolumn{2}{|c|}{$95 \%$ CI for Mean } & \multirow[b]{2}{*}{ Minimum } & \multirow[b]{2}{*}{ Maximum } \\
\hline & & & & & $\begin{array}{l}\text { Lower } \\
\text { Bound }\end{array}$ & $\begin{array}{l}\text { Upper } \\
\text { Bound }\end{array}$ & & \\
\hline ESSIX & 5 & 0.532 & 0.095 & 0.043 & 0.414 & 0.650 & 0.42 & 0.65 \\
\hline LEONE & 5 & 0.512 & 0.054 & $0.024^{-}$ & 0.445 & $0.579^{-}$ & $0.45^{\circ}$ & 0.58 \\
\hline ERKODENT & 5 & 0.552 & 0.047 & 0.021 & 0.494 & $0.610^{-}$ & $0.49^{\circ}$ & $0.60^{\circ}$ \\
\hline BIO-ART & 5 & $0.600^{\circ}$ & 0.085 & 0.038 & 0.494 & $0.706^{-}$ & $0.50^{-}$ & $0.69^{\circ}$ \\
\hline Total" & 20 & 0.549 & 0.075 & $0.017^{-}$ & 0.514 & 0.584 & 0.42 & $0.69^{\circ}$ \\
\hline
\end{tabular}

SD - Std. Deviation, CI - Confidence Interval

\begin{tabular}{|c|c|c|c|c|c|c|}
\hline $\begin{array}{c}\text { ONE-WAY } \\
\text { ANOVA }\end{array}$ & $\begin{array}{c}\text { Sum of } \\
\text { Squares }\end{array}$ & df & $\begin{array}{c}\text { Mean } \\
\text { Square }\end{array}$ & F & Sig. \\
\hline $\begin{array}{c}\text { Groups } \\
\text { [Upper arch] }\end{array}$ & Between Groups & 0.011 & 3 & 0.004 & 1.826 & 0.183 \\
\hline $\begin{array}{c}\text { Groups } \\
\text { [Lower arch] }\end{array}$ & Tothin Groups & 0.033 & 16 & 0.002 & & \\
\hline & Bitwin Groups & 0.044 & 19 & & & \\
\hline
\end{tabular}

Table 4

ONE-WAY ANOVAANALYSIS TESTING FOR DIFFERENCES IN NET MASS LOSS BETWEEN THE FOUR GROUPS IN EACH $\mathrm{ARCH}$ 


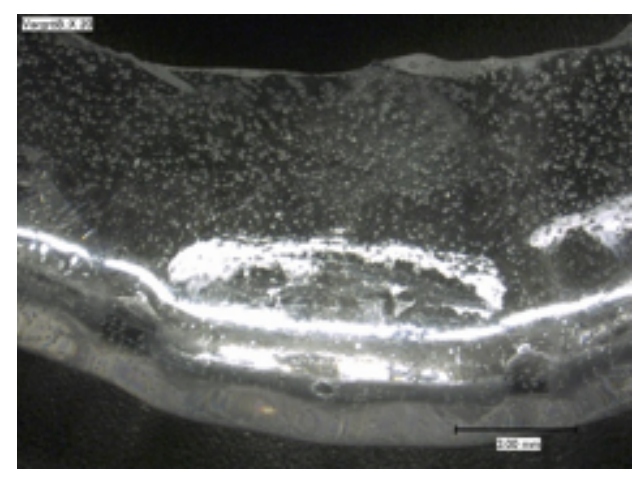

Fig. 6.1. ESSIX

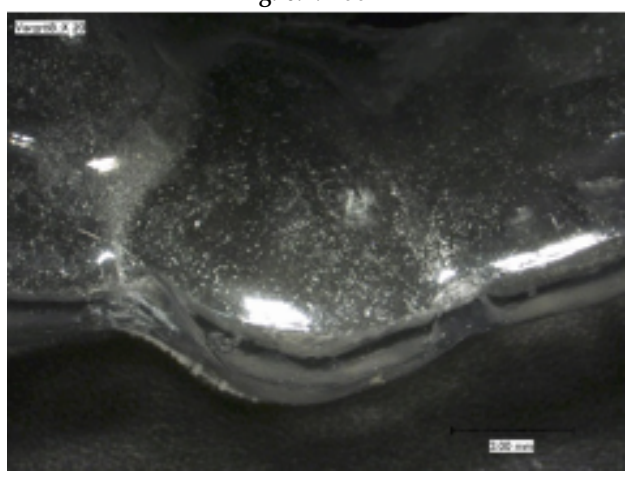

Fig. 6.2. LEONE

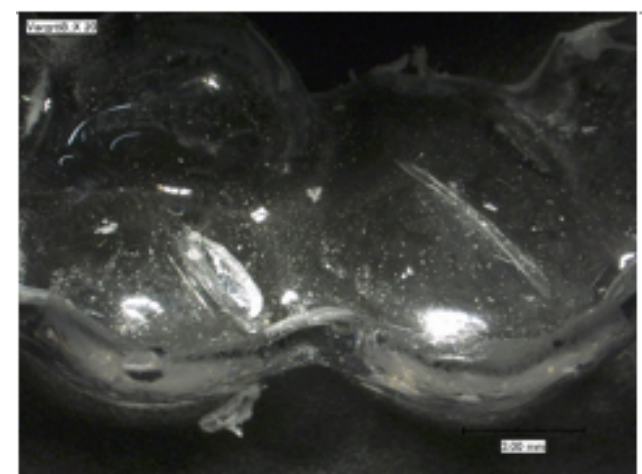

Fig. 6.3. ERKODENT

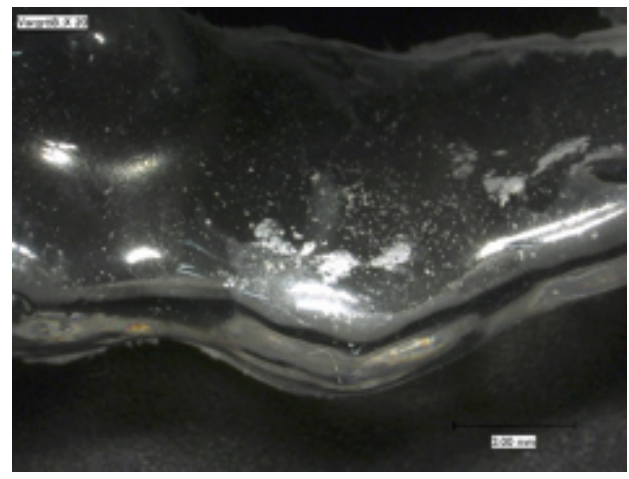

Fig. 6.4. BIO-ART

Fig. 6. Wear surfaces on the VFRs at level of the inferior canine, under the digital microscope (20X magnification).
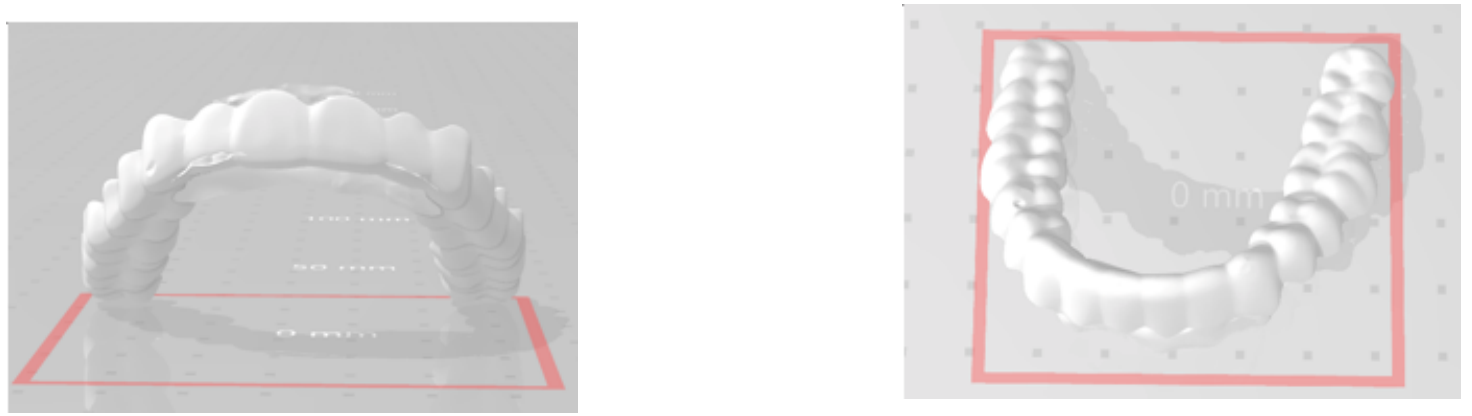

Fig. 7. GOM surfaces of the upper and lower VFRs from LEONE.

the accelerated wear degree of the VFRs we used a $600 \mathrm{~N}$ loading force, for 10000 cycles, with a rotation angle of 3 degrees. Even though a higher number of cycles was used, the VFR materials did not show evident tear points or perforations, probably because the load was distributed on a wider surface, thus the localized pressure at the contact points being reduced.

\section{Conclusions}

No statistically significant differences were found in net mass loss after wear simulations, between the four groups (Essix, Leone, Erkodent, Bio-Art) of polyethylene terephthalate glycol (PETG) vacuum-formed orthodontic retainers.

Visually inspecting and characterizing surfaces, under the digital microscope proved difficult on VFR materials because of the surface shine, how ever, several wear areas were identified, having various degrees of roughness, but, overall, consistent between the four groups, with no evident tear points or perforations.

Future studies, larger samples and better adapted protocols to real-life conditions might help better understanding the behavior of these thermoplastic materials in order to achieve optimal performance and reliability.
Acknowledgments: This work was supported by a mobility grant of the Romanian Ministry of Research and Innovation, CNCS - UEFISCDI, P1-1.1-MC-2018-1800 within PNCDI III.

\section{References}

1.TANCU, M. C., PANTEA, M., TOTAN, A., TANASE, M., IMRE, M., 3D Printed Dental Models, A comparative analysis, Mat. Plast. 56, no. 1, 2019, p.51-56

2.CAPLESCU, C., MARSAVINA, L., BORDEASU, I., SECHEI, R. M., The Fracture of Polyurethane Materials in the Presence of Stress Concentrators, Mat. Plast. 47, no. 3, 2010, p.379-382

3.BIRIS, C., BECHIR, E.S., BECHIR, A., MOLA, F.C., BADIU, A.V., OLTEAN, C., ANDREESCU, C., GIOGA, C., Evaluations of Two Reinforced Polymers Used as Metal-Free Substructures in Fixed Dental Restorations, Mat. Plast. 55, no. 1 2018, p.33-37

4.LITTLEWOOD, S.J., An Introduction to Orthodontics, 5th edition, Oxford Universtity Press, LITTLEWOOD, S.J., MITCHELL, L. (eds.), New York, 2019, p. 204.

5.MITELEA, I., VARZARU, N., BORDEASU, I., SCURTU, D., Failure Analysis of High Frequency Welding Fixed J oints of Thermoplastic Polymers, Mat. Plast. 46, no. 4, 2009, p. 439-443

6.POP, D.A., MALAESCU, R., HOSSZU, T., ROTAR, R., GOGUTA, L., DUMA, F.V., NEGRUTIU, M.L., SINESCU, C., JIVANESCU, A., Fracture Resistance of CAD/CAM Versus Traditional Interim Fixed Dental Prostheses, Mat.Plast. 55, no. 3, 2018, p.361-363 
7.LITTLEW OOD, S.J., KANDASAMY, S., HUANG, G., Aust. Dent. J., 62, no. 1 Suppl, 2017, p. 51-57.

8.LITTLEWOOD, S.J., RUSSELL, J.S., SPENCER, R.J ., Orthod. Updat, 2, 2009, p. 43-49.

9.MELROSE, C., MILLETT, D.T., Am. J. Orthod. Dentofacial Orthop., 113, no. 5, 1998, p. 507-514.

10.CERNESCU, A., FAUR, N., BORTUN, C., HLUSCU, M., A methodology for fracture strength evaluation of complete denture, ENGINEERING FAILURE ANALYSIS, 18(5), 2011, p. 1253-1261

11.SINESCU, C., NEGRUTIU, M., TATAR, R., TERTELEAC, A., NEGRU, R., HLUSCU, M., CULEA, L., ROMINU, M., MARSAVINA, L., HUGHES, M., BRADU, A., DOBRE, G., MARCAUTEANU, C., DEMJAN, E., PODOLEANU, A., Investigation of osteoconductive bone substitute by particles analysis, numerical simulation and optical coherence tomography, Conference on Lasers in Dentistry XV. Proceedings of SPIE-The International Society for Optical Engineering, vol. 7162, 2009, DOI: $10.1117 / 12.809688$

12.ROWLAND, H., HICHENS, L., WILLIAMS, A., HILLS, D., KILLINGBACK, N., EWINGS, P., CLARK, S., IRELAND, A.J ., SANDY, J.R., Am. J. Orthod. Dentofac. Orthop., 132, no. 6, 2007, p. 730-737. 13.HICHENS, L., ROWLAND, H., WILLIAMS, A., HOLLINGHURST, S., EWINGS, P., CLARK, S., IRELAND, A., SANDY, J., Eur. J. Orthod., 29, no. 4, 2007, p. 372-378.

14.REN, S.S., DAl, X., YING, M., WANG, W.X., CHANG, J., HOU, Z.M., Zhonghua Kou Qiang Yi Xue Za Zhi, 53, no. 9, 2018, p. 599-603.

15.SALEH, M., HAJEER, M.Y., MUESSIG, D., Eur. J. Orthod., 39, no. 4, 2017, p. 453-461.

16.GARDNER, G.D., DUNN, W.J., TALOUMIS, L., Am. J. Orthod. Dentofac. Orthop., 124, no. 3, 2003, p. 294-297.

17.CAMPBELL, A., MCMULLAN, R., WINNING, L., BAXTER, K., COLLINS, J., LUNG, Z., Br. Orthod. Soc. Clin. Eff. Bull., 23, 2009, p. $20-22$.
18.RAJ A, T.A., LITTLEW OOD, S.J ., MUNYOMBWE, T., BUBB, N.L., Angle Orthod., 84, no. 4, 2014, p. 656-664.

19.MAI, W., HE, J., MENG, H., JIANG, Y., HUANG, C., LI, M., YUAN, K., KANG, N., Am. J. Orthod. Dentofac. Orthop., 145, no. 6, 2014, p. 720727.

20.MOSHKELGOSHA, V., SHOMALI, M., MOMENI, M., J . Dent. Biomater., 3, no. 2, 2016, p. 248-253.

21.AHDAB, H., In vitro Evaluation of Wear Properties of Six Orthodontic Thermoplastic Retainer Materials, Oregon Health and Sciences University, Portland, OR, 2016, p. 1-76, Available from: http:// digitalcommons.ohsu.edu/etd/3865.

22.ILIESCU, N., ATANASIU, C., HADAR, A., The simulation of the mechanical behaviour of engineering structures on models made of plastic materials with special properties, Mat. Plast. 42, no.1, 2005, p.72-76

23.GHEORGHE, A., HADAR, A., APOSTOLESCU, Z., AMZA, C. G., ANTON, $L$., Determination through numerical computation of the designed and functional parameters of ultra acustic systems for ultrasonic welding of intelligent composite materials, Mat. Plast. 44, no. 2, 2007, p.121-128

24.GOANTA, V., HADAR, A., LEITOIU, B., Experimental Procedure Designed to Determine the Elastic Characteristics of Fiber-Reinforced Polymeric Composite Materials, Mat. Plast. 47, no. 4, 2010, p.450-456 25.TABACU, S., HADAR, A., MARINESCU, D., IVANESCU, M., BALASOIU, $V$., Numerical Procedures for the Improvement of the Structural Response of Thermoplastic Manufactured Parts, Mat. Plast. 46, no. 2, 2010, p.192-197

Manuscript received: 21.05.2019 